\title{
Insecticidal and antifeedant activity of Melia azedarach (L.) fruits, on Spilosoma obliqua (Walker) (Lepidoptera: Arctiidae) larvae
}

\author{
Tarkeshwar $^{1}$, Kapinder ${ }^{1}$ and Ashok Kumar Singh ${ }^{2}$ \\ ${ }_{1,1,2}$ (Department of Zoology, University of Delhi, India)
}

\begin{abstract}
The survivorship bioassay conducted with the M. azedarach fruit extracts on the first instar larvae showed a very high toxicity, most effective being methanol sequential fruit extract and this extract when tested on $4^{\text {th }}$ and $5^{\text {th }}$ instar larvae had significant antifeedant activity at all the concentrations. Nevertheless, there was less toxicity seen in the hexane extract test whereas, strong larvicidal activity of methanol sequential extract was observed with the neonate larvae reflects the higher susceptibility of neonate to this extract and thus indicating that to control the spread of this pest by targeting at the earlier stages. In addition, the results of the reduced leaf area consumed and fecal pellets excreted indicated that the high potency of the various extracts of M. azedarach, methanol sequential in particular, could be harnessed and its application would result in considerable reduction in the feeding damage by the pest.
\end{abstract}

Keywords: Spilosoma, Melia, survivorship, antifeedant, castor

\section{Introduction}

Spilosoma obliqua Walker (Lepidoptera: Arctiidae), commonly known as Bihar hairy caterpillar is a polyphagous and sporadic pest attacking nearly 126 plants species distributed in 24 families (Singh and Varathrajan, 1999). This pest has been reported to cause extensive damage to crops such as oilseeds, pulses, vegetables, fodder, fiber crops, fruit trees (Singh and Singh, 1992). Menace of this pest is continuously increased in India and its Subcontinents (Deshmukh et al., 1976). The larvae of this insect are voracious feeder and its population often reaches epidemic level when they defoliate plants and move from field to field finishing the vegetation of the area of their visit (Singh and Bhattacharya, 1994).

Approximately one third of the global food production is destroyed annually by insect pests. Synthetic pesticides have been the most effective means of pest control but, continuous and indiscriminate use of insecticides over the years has resulted in the development of resistance to certain molecules belonging to different classes of insecticides in different parts of the world. The failure of chemical pesticides to control the pest and growing public concern for safe food and a healthy environment have catalyzed the search for environmental friendly control methods for management of this pest.

The use of botanical resources for agrochemical purpose is one of the important alternatives to manage insect-pests in place of synthetic insecticides. The activity of crude plant extracts is often attributed to the complex mixture of active compounds that alter the behavioural and physiological aspects of insects which reduces the potential chances of insect resistance to the natural complex (Feng \& Isman, 1995).

Numerous plant species have been reported to possess pest control properties, among these, Chinaberry, Melia azedarach is one of such plant belonging to family meliacae whose bio-efficacy has long been realized for its highly effective properties against a number of insect pests (Schmutterer, 1995, Gajmer et al., 2002 and Hammad and McAuslane, 2006). Limonoids from this plant are known to exhibit insect antifeedance, oviposition repellency and growth regulatory effect (Carpinella et al., 2002, 2003).

A number of reports on inhibitory activities of plant botanicals have been screened against S. obliqua (Tripathi et al., 1990, Dubey et al., 2004). Though, several plant botanicals have been screened for the search of promising control measures of $S$. obliqua, but reports about the effect of $M$. azedarach, against $S$. obliqua are scarce. So, our present work carried out to investigate the effect of $M$. azedarach fruit extracts, on survival and feeding of S. obliqua larvae under laboratory conditions

\section{Rearing of Spilosoma obliqua}

\section{Materials And Methods}

The mass culture of $S$. obliqua was established from the larvae collected from infested castor leaves from agricultural fields of Delhi near Yamuna river bank. The insects were reared in laboratory on castor leaves (Ricinnus communis L.) in plastic jars $(14.5 \mathrm{~cm}$ dia. X $17.5 \mathrm{~cm} \mathrm{ht.)} \mathrm{until} \mathrm{pupation} \mathrm{and} \mathrm{adult} \mathrm{emergence,}$ subsequently eggs were harvested till hatchling and a stock culture was maintained on castor leaves under ambient conditions (temperature $26 \pm 22^{\circ} \mathrm{C}$, relative humidity $70 \pm 5 \%$ and 12:12 h L:D photoperiod) and required stage of larvae were taken from the culture on the day of bioassay. 


\section{Preparation of Extract}

Ripe fruits of M. azedarach were collected from trees in Delhi University campus in summer season. These fruits were washed thoroughly in running water and shade dried for a week. The whole fruits were grinded in stainless steel blender (Phillips, India) and kept for further use.

\subsection{Solvent Extraction}

Two different extracts of M. azedarach fruits were prepared. First in hexane, and then sequentially in methanol with residues obtained after hexane extraction.

Sequential extracts of fruits with hexane and methanol were obtained as the procedure developed by Ahmed and Bhattacharya, (1991) and Juan et al., (2000) with certain modification. $50 \mathrm{~g}$ of crushed powder was immersed in $250 \mathrm{ml}$ of hexane in a glass beaker (Borosil) and stirred by magnetic stirrer for $1 \mathrm{~h}$. This solution was left undisturbed for $12 \mathrm{~h}$ (overnight) and was filtered through Whatman no.1 filter paper. Liquid part was decanted in a fresh beaker, and $250 \mathrm{ml}$ of hexane was further added to residue followed by tremendous stirring, decanted and pooled with the $1^{\text {st }}$ decanted aliquot. This process was repeated thrice for maximum extraction. The solid residue, so left, was air dried and further extracted with methanol following a similar procedure discussed above. The two extracts so obtained were concentrated separately in a rotary evaporator at $35-40^{\circ} \mathrm{C}$, under reduced pressure that yielded a viscous dark-yellow oily residue from hexane and dark-red, semi-solid residue from methanol extract. These were kept in small vials $(15 \mathrm{ml}$, Borosil) capped and preserved in refrigerator $\left(8-12^{0} \mathrm{C}\right)$ for further use.

\subsubsection{Preparation of Treatment Solution}

Control

Control solution was prepared by mixing $1 \mathrm{ml}$ of hexane in $9 \mathrm{ml}$ of distilled water mixed with $0.5 \%$ Triton-X 100 as an emulsifier to make the volume of $10 \mathrm{ml}$.

Treatment

Five concentrations were made namely, 1000, 2000, 3000, 4000 and 5000 ppm by dissolving 10, 20, 30,40 and $50 \mathrm{mg}$ of respective extract in control solution individually so as to make it $10 \mathrm{ml}$ in each case, except for $0.5 \%$ Triton-X100 in case of methanol sequential.

\section{Bioassays}

\subsection{Survivorship Bioassay}

Neonate larvae $(0-12 \mathrm{~h}$ old $)$ were used for this bioassay with both extracts. Fresh and tender leaves of castor were cut into $2 \mathrm{~cm}$ dia. circular discs and dipped individually for $15 \mathrm{~s}$ in respective concentrations of hexane or methanol sequential extracts, after that these were air dried and then placed in circular plastic boxes (5 $\mathrm{cm}$ dia. X $5 \mathrm{~cm} \mathrm{ht.)} \mathrm{lined} \mathrm{with} \mathrm{moist} \mathrm{tissue} \mathrm{paper,} \mathrm{similarly} \mathrm{for} \mathrm{control,} \mathrm{leaf} \mathrm{discs} \mathrm{dipped} \mathrm{in} \mathrm{control} \mathrm{solution.}$ Neonate larvae were released on each leaf disc and mean survival percentage of larvae was observed after $24 \mathrm{~h}$ and $48 \mathrm{~h}$ of treatment. Each replicate consist of 20 larvae and bioassay were repeated 5 times.

Percent survival was calculated as:-

$$
\frac{\text { No. of larvae surviving in treatment }}{\text { Initial no. of larvae per replicate }} \times 100
$$

\subsection{Antifeedant bioassay}

The antifeeding potential of the methanol sequential extract was tested by leaf disc method (Abdelgaleil and Nakatani, 2003) against $4^{\text {th }}$ and $5^{\text {th }}$ instar larvae of S. obliqua. Freshly excised castor leaf was trimmed to the size of $5 \mathrm{~cm}$ diameter and these were treated as the procedure discussed above. Individual leaf discs were kept in the center of a Petri dish $\left(10 \mathrm{~cm}\right.$ diameter). Two freshly moulted $4^{\text {th }}$ or $5^{\text {th }}$ instar larvae were placed on the leaves in each Petri dish. After $24 \mathrm{~h}$, the leaf area consumed by the larvae was traced on graph paper and measured (Singh and Singh, 1993; Sarma and Kalita, 2001), whereas, the number of fecal pellets was also counted for the antifeedant activity of the extract. Three replicates of each concentration were carried out.

An antifeedant index (AI) was calculated using the formula $\mathrm{AI}=(\mathrm{C}-\mathrm{T} / \mathrm{C}+\mathrm{T}) \mathrm{X} 100$ where, $\mathrm{C}$ is for leaf area consumed in control and $\mathrm{T}$ is for leaf area consumed by the insect in treatment (Isman et al., 1990). Whereas, number of fecal pellets was calculated by using the formula, (Shukla et al., 2000).

$$
\mathrm{AI}=1-\frac{\text { No. of fecal pellets in treatment }}{\text { No. of Fecal pellets in control }} \times 100 .
$$

All the bioassays were conducted in BOD incubator maintained at $26 \pm 1{ }^{\circ} \mathrm{C}$ temperature and $70 \pm 5 \%$ relative humidity and 12:12 h L:D photoperiod. 


\section{Statistical analysis}

Data for the responses of the insects under different conditions were subjected to one-way Analysis of Variance (ANOVA). Means were compared by Tukey's test to analyze the significant difference between control and different concentrations also among different concentrations. The statistical analysis of various responses of S. obliqua was performed on computer software program Sigma Stat 2.0 (Jandel Scientific, 1995).

\section{Survivorship bioassay}

\section{Results}

\subsection{4 h treatment}

After $24 \mathrm{~h}$, the mean survival of $S$. obliqua neonate larvae fed on control leaf, and leaf discs treated with different concentrations of hexane extract was statistically equal $(\mathrm{p}>0.05)$.

However in case of methanol sequential, neonate larvae fed on treated leaf discs for $24 \mathrm{~h}$, showed a negative correlation between extract concentration and survival percentage (Table 1). The mean survival percentage of larvae on all the concentrations of methanol sequential extract were significantly lower as compared to control $(\mathrm{p}<0.05)$. Survivorship of larvae at 1000,2000 and $3000 \mathrm{ppm}$ concentration was significantly reduced to $51 \%, 49 \%$ and $42 \%$, than the survivorship of larvae (100\%) at control. Survivorship sharply declined to $23 \%$ and $22 \%$ at 4000 and $5000 \mathrm{ppm}$ respectively, and this was significantly lowest as compared to the survivorship of larvae on rest of the concentrations of extract $(\mathrm{p}<0.05)$.

\subsection{8 h treatment}

The mean survivorship of larvae released on hexane extract treated leaf discs, decreased with the increase in concentration after $48 \mathrm{~h}$ of treatment (Table 1). Significantly lowest survivorship was observed at $5000 \mathrm{ppm}(61 \%)$, as compared to 1000 (94\%), $2000 \mathrm{ppm}(96 \%)$, and control $(100 \%)(\mathrm{p}<0.05)$. Whereas, the larval survivorship on $3000(79 \%)$ and $4000 \mathrm{ppm}(72 \%)$ treated leaf was not significant from $5000 \mathrm{ppm}$ $(\mathrm{p}>0.05)$.

Whereas, the larvae fed on leaf discs having methanol sequential treatment could not survive for $48 \mathrm{~h}$, and all of them died at all the tested concentrations.

Table1: Survival of S. obliqua larvae on different treatments of M. azedarach fruit extract

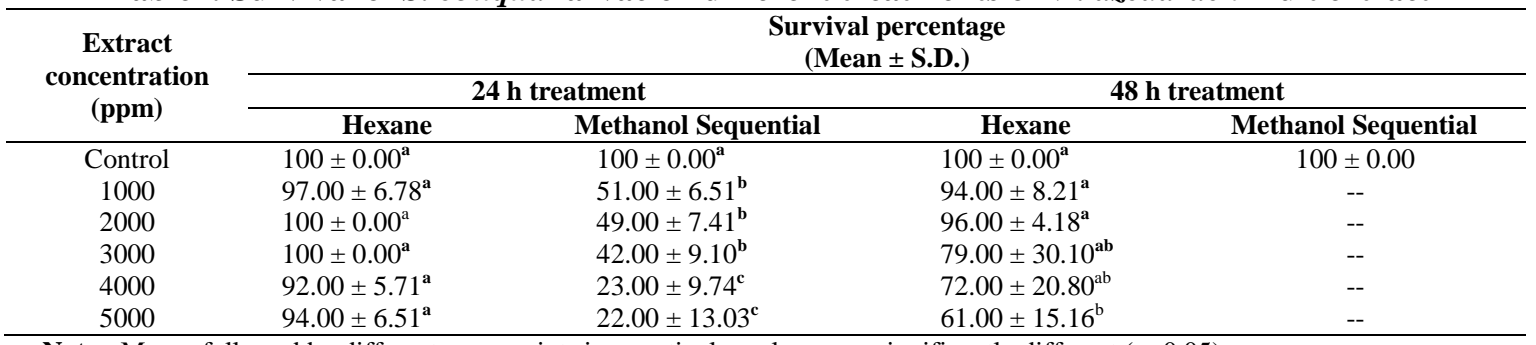

Note: Means followed by different superscripts in a particular column are significantly different $(\mathrm{p}<0.05)$, (--) All the larvae died at this concentration.

\section{Antifeedant bioassay}

Antifeedant activity was measured for the methanol sequential extract as this was found most effective at all concentrations than hexane extracts in survivorship bioassay. The antifeedant effect of methanol sequential was evident with respect to the following parameters:

- Leaf area consumption

- Number of fecal pellets

\subsection{Leaf area consumption}

The average leaf area consumed by the $4^{\text {th }}$ instar larvae was significantly higher in control as compared to all treatments $(p<0.05)$ (Table 2$)$. Leaf area consumption by $4^{\text {th }}$ instar larvae on leaves treated with 1000 ppm concentration was significantly lower $\left(2.46 \mathrm{~cm}^{2}\right)$ than control $\left(3.55 \mathrm{~cm}^{2}\right)(\mathrm{p}<0.05)$. The leaf consumption at 2000 and 3000 ppm was prevented only up to 1.49 and $1.16 \mathrm{~cm}^{2}$, respectively, though the difference between them being not significant but, this consumption was significantly lower than the area consumed at $1000 \mathrm{ppm}$ $(\mathrm{p}<0.05)$, and reduced to almost half to the area consumed at control. However, mean consumption of leaf area $\left(0.43 \mathrm{~cm}^{2}\right)$ was significantly lowest at $4000 \mathrm{ppm}$. Whereas, at $5000 \mathrm{ppm}$, the larvae could not survive to feed on the leaf discs.

Significant inhibition of this extract on the feeding was also observed in case of $5^{\text {th }}$ instar larvae. Leaf area consumption by larvae on control was maximum $\left(9.69 \mathrm{~cm}^{2}\right)$, which was statistically reduced as the concentration increased. However, feeding damage was completely inhibited at $5000 \mathrm{ppm}$. (p<0.05). Moreover, 
in both the stages, a declining trend in leaf area consumption with the increase of extract's concentration was observed.

\subsection{Excretion of fecal pellets}

Feeding deterrence on treated leaf surface was also confirmed by number of fecal pellets excreted by the larvae. The results showed a significant reduction in the number of fecal pellets excreted by larvae, fed on leaf discs treated with extract as compared to control ( $\mathrm{p}<0.05)$ (Table 2). At $5000 \mathrm{ppm}$, both the $4^{\text {th }}$ and $5^{\text {th }}$ instar larvae did not feed and as such no fecal pellets were observed, which further confirmed total feeding inhibition. Lowest number of fecal pellets $(\sim 18)$ were counted in both larval instars that fed on leaf discs treated with 4000 ppm concentration, whereas, highest number of fecal pellets were recorded in the larvae $\left(74.67\right.$ and 64.00 for $4^{\text {th }}$ and 5th instars, respectively) that fed on leaf disc treated with $1000 \mathrm{ppm}$. However, the number of pellets was significantly lower as compared to those fed on control leaf $(\mathrm{p}<0.05)$.

Table2: Feeding behaviour of $S$. obliqua larvae on castor leaf disc treated with $M$. azedarach fruits extract

\begin{tabular}{|c|c|c|c|c|}
\hline \multirow{2}{*}{$\begin{array}{c}\text { Extract } \\
\text { concentration } \\
(\mathbf{p p m})\end{array}$} & \multicolumn{2}{|c|}{$\begin{array}{l}\text { Leaf area consumption }\left(\mathrm{cm}^{2}\right) \\
(\text { Mean } \pm \text { S.D. })\end{array}$} & \multicolumn{2}{|c|}{$\begin{array}{l}\text { No. of Fecal pellets } \\
\quad(\text { Mean } \pm \text { S.D. })\end{array}$} \\
\hline & $4^{\text {th }}$ instar & $5^{\text {th }}$ instar & $4^{\text {th }}$ instar & $5^{\text {th }}$ instar \\
\hline Control & $3.55 \pm 0.40^{\mathrm{a}}$ & $9.69 \pm 0.07^{\mathrm{a}}$ & $106.33 \pm 2.51^{\mathrm{a}}$ & $85.33 \pm 4.51^{\mathrm{a}}$ \\
\hline 1000 & $2.46 \pm 0.09^{\mathbf{b}}$ & $7.27 \pm 0.18^{\mathbf{b}}$ & $74.67 \pm 3.05^{\mathbf{b}}$ & $64.00 \pm 2.64^{b}$ \\
\hline 2000 & $1.49 \pm 0.14^{\mathrm{c}}$ & $5.23 \pm 1.27^{\mathbf{c}}$ & $47.00 \pm 13.22^{\mathrm{c}}$ & $34.00 \pm 3.61^{\mathrm{c}}$ \\
\hline 3000 & $1.16 \pm 0.37^{\mathrm{c}}$ & $2.21 \pm 0.68^{d}$ & $34.33 \pm 9.02^{\text {cd }}$ & $23.00 \pm 1.73^{\mathrm{d}}$ \\
\hline 4000 & $0.43 \pm 0.13^{d}$ & $1.78 \pm 0.45^{\mathrm{d}}$ & $18.67 \pm 5.87^{\mathrm{d}}$ & $18.00 \pm 5.29^{d}$ \\
\hline 5000 & -- & -- & -- & -- \\
\hline
\end{tabular}

Note: Means followed by different superscripts in a particular column are significantly different $(\mathrm{p}<0.05),(--)$ no feeding at this concentration.

\subsection{Antifeedant index}

Antifeedant index (AI) of larvae on the basis of leaf area consumption increased with the increase in concentration of extract. AI values for $4^{\text {th }}$ instar larvae ranged from 18.15 to $100 \%$, and for the $5^{\text {th }}$ instar larvae from 14.29 to $100 \%$ (Table 3), from 1000 to $5000 \mathrm{ppm}$. Antifeedant index of $4^{\text {th }}$ instar larvae was statistically significant at different concentration except between 2000 and $3000 \mathrm{ppm}$. In case of $5^{\text {th }}$ instar larvae, the antifeedance was statistically different between all the concentrations except between 1000 and 2000 ppm, and also between 3000 and $4000 \mathrm{ppm}$. Moreover, a positive correlation was recorded between the AI value and the concentration of the methanol sequential extract.

Table 3: Antifeedant index S. obliqua larvae against methanol sequential extract of $M$. azedarach fruits

\begin{tabular}{|c|c|c|c|c|}
\hline \multirow{2}{*}{$\begin{array}{c}\text { Extract } \\
\text { concentration } \\
(\text { ppm })\end{array}$} & \multicolumn{2}{|c|}{ Leaf area consumption } & \multicolumn{2}{|c|}{ No. of Fecal pellets } \\
\hline & $4^{\text {th }}$ instar & $5^{\text {th }}$ instar & $4^{\text {th }}$ instar & $5^{\text {th }}$ instar \\
\hline 1000 & $18.15^{\mathrm{a}}$ & $14.29^{\mathrm{a}}$ & $29.33^{\mathrm{a}}$ & $24.33^{\mathrm{a}}$ \\
\hline 2000 & $40.95^{\mathbf{b}}$ & $30.55^{\mathrm{ab}}$ & $55.33^{\mathbf{b}}$ & $59.66^{\mathbf{b}}$ \\
\hline 3000 & $51.23^{\mathrm{bc}}$ & $63.26^{\mathrm{c}}$ & $66.00^{\mathrm{bc}}$ & $72.66^{\mathrm{c}}$ \\
\hline 4000 & $79.03^{\mathrm{d}}$ & $69.13^{\mathrm{cd}}$ & $82.33^{\text {cd }}$ & $78.33^{\text {cd }}$ \\
\hline 5000 & $100^{\mathrm{e}}$ & $100^{\mathrm{e}}$ & $100^{\mathrm{d}}$ & $100^{\mathrm{e}}$ \\
\hline
\end{tabular}

Note: Means followed by different superscripts in a particular column are significantly different $(\mathrm{p}<0.05)$

\section{Discussion}

The study reveals that Melia azedarach fruits contain compounds that possess toxic as well as antifeedant properties against Spilosoma obliqua larvae. Crude extracts from the fruit of M. azedarach have adverse effects on the survival of $S$. obliqua larvae. The larvae were able to tolerate and effect was not very apparent for short duration feeding on non-polar hexane extract of $M$. azedarach treated leaves. However, exposure of larvae for longer duration to this extract had apparent adverse effect on the survival of larvae. Similar effects were also reported by non-polar ether extracts of Melia fruits on nymphs of white fly Bemisia tabaci (Hammad et al., 2000).

Methanol sequential extract of $M$. azedarach had adverse effect on the survival of larvae which was dependent on both concentration and length of feeding duration, even the lowest concentration cause $100 \%$ mortality of $S$. obliqua larvae. The results suggest the methanol sequential extract is more potent than hexane extract against the neonate $S$. obliqua larvae. Schmidt et al., (1997) observed that toxic effects of Melia extract depend on the degree of purification. They found that methanolic extract, when purified through solvent 
partitioning, was more efficient against lepidopteran pest A. ipsilon and $S$. littoralis, than the crude methanol extract. Similar finding had been also reported by Breuer and Schmidt (1995 and 1996) on S. frugiperda.

Lower consumption and higher mortality of larvae on methanol sequential extract indicate that extract has both the feeding deterrent and toxic component against S. obliqua larvae. The possible explanation for this effect might be due to the presence of active compounds in this extract. Although, large number of biological active compounds such as limonoids including salannin, sendanin, nimbolins, trichilins, azadirachins, meliacarpins and meliartenin has been isolated from the fruits and seeds of Melia tree but the most notable constituent is toosendanin, (Schmidt et al., 1998; Hammad et al., 2001; Schmutterer, 2002; Bahncio et al., 2003).

Potential of methanol sequential extract can be evaluated as feeding deterrent, that $100 \%$ antifeedance at $5000 \mathrm{ppm}$ caused complete inhibition of larval feeding, which were starved to death. The larvae succeed to feed on the plant surface treated with lower concentration of extract, but with lower feeding preference. The effect of suppressed feeding reflected both by leaf area consumption and fecal pellets of larvae. This observed effect might be due to the presence of secondary plant chemicals, especially meliartenin and toosendanin, in the crude methanolic sequential extract. There are similar reports about the antifeedant activity of crude $M$. azedarach extracts against important agricultural pests, (Valladares et al., 1997, Juan et al., 2000, Nathala and Dhingra, 2005).

In the present investigation, a dose dependent feeding deterrent activity of methanolic sequential extract of M. azedarach fruits is also confirmed by fecal pellets counts which reflected strong feeding inhibition as well as reduced metabolism of ingested food. Schmidt et al., (1997) also found significant reduction in the number of fecal pellets of A. ipsilon and S. littoralis due to feeding inhibition potency. They observed feeding deterrency was inversely proportional to the number of fecal pellets produced.

\section{Conclusion}

The findings of this study are important and may be helpful in the management of Bihar hairy caterpillar, $S$. obliqua. The present study suggests that $M$. azedarach has tremendous potential for the management of $S$. obliqua in the field. Moreover, complex mixtures of active constituents, as found in botanical insecticides, may also be advantageous in terms of pest resistance and behavioral desensitization (Bomford and Isman, 1997). This system of management will not only be environmental friendly but also sustainable.

\section{Acknowledgements}

We thank University of Delhi, India, for providing facilities in the Department of Zoology, during this study. We gratefully acknowledge Research Fellowship provided by the University Grants Commission for this work.

\section{References}

[1] Y.R. Singh and R. Varatharajan. Host range of Bihar hairy caterpillar, Spilosoma obliqua (Walker) (Arctiidae: Lepidoptera). Hexapoda, 1999, 11 (2): 65-74

[2] I. Singh and G. Singh. Assessment of foliage loss caused by different larval instars of Bihar hairy caterpillar, Spilosoma obliqua Walker on sunflower. J. Insect Sci., 1992, 6 (2): 185-186.

[3] P.D. Deshmukh, Y.S. Rathore and A.K. Bhattacharya. Host range of Bihar hairy caterpillar Diacrisia obliqua Walker. Bull. Ent., 1976, 17: 85-99.

[4] S.P. Singh and A.K. Bhattacharya. Development behaviour of Spilosoma obliqua Walker on the semisynthetic diets prepared with a mixture of flour of pea and soybean. Indian J. Ent., 1994, 56 (1): 83-86.

[5] B. Fakrudin, V. Kumar, K.B. Krishnareddy, B.V. Patil and M.S. Kuruvinashetti. Morphometric differences between pyrethroid resistant and susceptible populations of cotton bollworm, Helicoverpa armigera. Resistant Pest Manag. Newsl., 2004, 13: 18-19.

[6] B.E. Tabashnik. Resistance risk management: realized heritability of resistance to Bacillus thuringiensis in diamondback moth (Lepidoptera: Plutellidae), tobacco budworm (Lepidoptera: Noctuidae), and Colorado potato beetle (Coloeptera: Chrysomelidae). Journal of Economic Entomology, 1992, 85:1551-.1559.

[7] R. Feng and M.B. Isman. Selection for resistance to azadirachtin in the green peach aphid Myzus persicae. Experientia, 1995, 51: 831-833.

[8] H. Schmutterer. The Neem Tree: Source of unique natural products for integrated pest management, medicine, industry and other purposes. (VCH Verlagsgesellschaft, Weinheim, 1995).

[9] T. Gajmer, R. Singh, R.K. Saini and S.B. Kalidhar. Effect of methanolic extracts of neem (Azadirachta indica A. Juss) and bakain (Melia azedarach L) seeds on oviposition and egg hatching of Earias vitella (Feb.) (Lep.,: Noctuidae). J. Appl. Ent., 2002, 126: 238-243.

[10] A.E.M. Hammad and H.J. McAuslane. Effect of Melia azedarach L. extract on Bamisia argentifolii (Hemiptera: Aleyrodidae) and its biological agent Eretmocerus rui (Hymenoptera: Aphelinidae). Environ. Ent., 2006, 35 (3): 740-745.

[11] M.C. Carpinella, M.T. Defago, G. Valladares and S.M. Palacios. Antifeedant and insecticide properties of a limonoid from Melia azedarach (Meliaceae) with potential use for pest management. J. Agric. Food Chem., 2003, 51: 369-374.

[12] C. Carpinella, C. Ferrayoli, G. Valladares, M. Defago and S. Palacios. Potent limonoid insect antifeedant from Melia azedarach. Biosci. Biotechnol. Biochem., 2002, 66 (8): 1731-1736.

[13] A.K. Tripathi, D. Singh and A.C. Jain. Persistency of tylophorine as an insect antifeedant against Spilosoma obliqua Walker. Phytothe. Res., 1990, 4 (4): 144-147. 
[14] A. Dubey, R. Gupta and B.S. Chandal. Efficacy of Acorus calamus, Vitex negundo and Ageratum conyzoides against Tobacco caterpillar Spilarcta obliqua Walker. Indian J. Ent., 2004, 66 (3): 238-240.

[15] S.R. Ahmed and A.K. Bhattacharya. Growth inhibitory effect of some plants for Spilosoma obliqua Walker. Indian J. Ent., 1991, $53(3): 453-474$

[16] A. Juan, A. Sans and M. Riba. Antifeedant activity of fruit and seed extracts of Melia azedarach and Azadirachta indica on the larvae of Sesamia nonagrioides. Phytoparacitica, 2000, 28 (4): 1-9.

[17] S.A.M. Abdelgaleil and M. Nakatani. Antifeeding activity of limonoids from Khaya senegalensis (Meliaceae). J. Appl. Ent., 2003, 127: 236-239.

[18] G. Singh and I. Singh. Comparative development and survival of Bihar hairy caterpillar (Spilosoma obliqua) at different temperatures and on different varieties of sunflower (Helianthus annuus) at Ludhiana. Indian J. Agri. Sci., 1993, 63 (7): 447-450.

[19] M. Sarma and J. Kalita. Assessment of foliage loss caused by different larval instars of Spilosoma obliqua on jute in Assam. $J$. Ecobiol., 2001, 13 (4): 313-315.

[25] M.B. Isman, O. Koul, A. Luczynski and A. Kaminski. Insecticidal and antifeedant bioactivities of neem oils and their relationship to azadirachtin content. J. Agric. Food Chem., 1990, 38: 1406-1411.

[20] Y.N. Shukla, R. Srivastava, A.K. Tripathi and V. Prajapati. Characterization of an Ursane triterpenoids from Centella asiatica with growth inhibitory activity against Spilarctia obliqua. Phram. Biol., 2000, 38 (4): 262-267.

[21] Jandel Sigma Stat. Computer software for statistical analysis. 1995.

[22] A.E.M. Hammad, N.M. Nemer, and N.S. Kawar. Efficacy of chinaberry tree (Meliaceae) aqueous extracts and certain insecticides against the pea leafminer (Diptera: Agromyzidae). J. Agri. Sci., 2000, 134: 413-420.

[23] J.R.Miller and T.A. Miler. Insect-Plant Interactions. (Springer-Verlag, New York, 1998).

[24] J.H. Wen and H. Schmutterer. Effect of extracts from fruit and leaves of Melia azedarach L. on Locusta migratoria migratorioides (R. \& F.). Anz. Schädlingskde., Pflanzenschutz, Umweltschutz, 1991, 64: 128-133.

[25] G.H. Schmidt, A.I. Ahmed and M. Breuer. Effect of Melia azedarach extract on larval development and reproduction parameters of Spodoptera littoralis (Boisd.) and Agrotis ipsilon (Hufn.) (Lep.,: Noctuidae). Anz. Schädlingskde., Pflanenschutz, Umweltschutz., 1997, 70:4-12.

[26] J.A. Leatemia, and M.B. Isman. Toxicity and antifeedant activity of crude seed extracts of Annona squamosa (Annonaceae) against lepidopteran pests and natural enemies. Int. J. Trop. Ins. Sci., 2004, 24 (1): 150-158.

[27] M. Breuer and G.H. Schmidt. Einfluß einer kurzzeutigen Behandlung mit Melia azedarach- über Blattmaterial auf Nahrungsaufnahme und Wachstum der larven von Spodoptera frugiperda (J.E. Smith) (Lepidoptera: Noctuidae). Zeitschr. Pflanzenkr. Pflanzench., 1995, 102 (6): 633-654.

[28] M. Breuer and G.H. Schmidt. Wirkung einer mit Melia azedarach-Extrakt behandelten raupendiät über auf Wachstum, entwicklung und fekundiät von Spodoptera frugiperda (J.E. Smith) (Lepidoptera: Noctuidae). Zeitschr. Pflanzenkr. Pflanzench., 1996, 103 (1): 171-194.

[29] G.H. Schmidt, H. Rembold, A.I. Ahmed and M. Breuer. Effect of Melia Azedarach fruit extract on the juvenile hormone titer and protein content in the haemolymph of two species of noctuid lepidopteran larvae [Insecta: Lepidoptera: Noctuidae]. Phytoparacitica, 1998, 26 (4): 283-291.

[30] A.E.M. Hammad, Zournajian and Talhouk. Efficacy of extracts of Melia azedarach L. callus, leaves and fruits against adults of the sweetpotato whitefly Bamicia tabaci (Hom.,: Aleyrodidae). J. Appl. Ent., 2001, 125: 483-488.

[31] T. Gajmer, R. Singh, R.K. Saini and S.B. Kalidhar. Effect of methanolic extracts of neem (Azadirachta indica A. Juss) and bakain $($ Melia azedarach L) seeds on oviposition and egg hatching of Earias vitella (Feb.) (Lep.,, Noctuidae). J. Appl. Ent., 2002, 126: 238-243.

[32] E. Banchio, G. Valladares, M. Defago, S. Palacios and C. Carpinella. Effect of Melia azedarach (Meliaceae) fruit extracts on the leafminer Liriomyza huidobrensis (Diptera: Agromyzoidae): Assessment in the laboratory and field experiments. Ann. Appl. Biol., 2003, 143: 187-193.

[33] E. Nathala and S. Dhingra. Chronic effect of Melia azedarach seed extracts on survival. Feeding, growth and development of Helicoverpa armigera. Ann. Pl. Protec. Sci., 2005, 13 (2): 292-297.

[34] G. Valladares, M.T. Defago, S. Plalacios and M.C. Carpinella. Laboratory evaluation of Melia azedarach (Meliaceae) extracts against the elm leaf beetle (Coleoptera: Chrysomelidae). J. Econ. Ent., 1997, 90: 747- 750. 